\title{
Licensed Nurse Staffing and Adverse Events in Hospitals
}

\author{
LYNN UnRUH, PhD, RN
}

Овјестіvе. To examine the changes in licensed nursing staff in Pennsylvania hospitals from 1991 to 1997, and to assess the relationship of licensed nursing staff with patient adverse events in hospitals.

Data Source. A convenience sample of all Pennsylvania, acute-care, hospitals, 1991 to 1997.

Study Design. The study first describes the percentage change of licensed nursing staff categories in Pennsylvania hospitals from 1991 to 1997 . Second, random effects Poisson regressions are used to assess the association of the numbers and proportions of licensed nurses with yearly iatrogenic lung collapse, pressure sores, falls, pneumonia, posttreatment infections, and urinary tract infections. Controls are the yearly number of patients, hospital acuity, and other hospital characteristics.

Data Collection. Secondary data containing patient- and hospital-level measures from three sources were recoded to establish the incidence of adverse events, aggregated to the

The introduction of prospective payments to hospitals in 1983 and price competition among hospitals because of managed care prompted a major restructuring of the hospital industry in the 1980s that accelerated in the 1990s..$^{1-3}$ Restructuring included downsizing of nurse staffing and changes in skill mix. ${ }^{2,4-5}$ By $1996,66 \%$ to $86 \%$ of respondents of nursing surveys reported staff reductions. At least

From the Department of Health Professions, College of Health and Public Affairs, Orlando, Florida.

Supported by grants from the National Science Foundation and the Agency for Health Care Policy and Research (now AHRQ).

Results were presented at the American Public Health Association meeting in November 2001. hospital level, and merged to form one data set.

PrinciPAl Funding. Licensed nurses' acuityadjusted patient load increased from 1991 to 1997. Licensed nurse/total nursing staff declined from 1994 to 1997. Greater incidence of nearly all adverse events occurred in hospitals with fewer licensed nurses. Greater incidence of decubitus ulcers and pneumonia occurred in hospitals with a lower proportion of licensed nurses.

Conclusions. This study suggests that licensed nurses' patient load began increasing in the 1990s. Adequate licensed nurse staffing is important in minimizing the incidence of adverse events in hospitals. Ensuring adequate licensed nurse staffing should be an area of major concern to hospital management. Improved measures of nurse staffing and patient outcomes, and further studies are suggested.

Key words: Nurse staffing; skill mix; medical error; adverse events; quality of care; patient outcomes. (Med Care 2003;41:142-152)

one-half reported increased utilization of assistive personnel.6-8 In a 1996 national survey of 7569 registered nurses (RNs) nearly two thirds reported a reduction in RNs, and two-fifths noted an increase in unlicensed personnel. In addition, two thirds said there had been an increase in the number of patients assigned to RNs, and three fourths believed that the acuity of patients had risen. ${ }^{8}$

Address correspondence and reprint requests to: Lynn Unruh, PhD, RN, Health Services Administration, Department of Health Professions, College of Health and Public Affairs, HPA-2, Rm 210-L, University of Central Florida, Orlando, FL 32816-2200. E-mail: lunruh@mail.ucf.edu

Received July 13, 2001; initial review October 9, 2001; accepted July 16, 2002. 
Nurses believe that these changes have negatively affected the quality of nursing care. They report "dangerously low staffing levels,"7 or "understaffing," 9 exacerbated by increased patient acuity and decreased length of stay. ${ }^{6}$ Many report an increase in medication errors, infections, pressure ulcers, skin breakdown, and patient injuries. ${ }^{8}$ By 2001, only $34 \%$ of US nurses felt that staffing was adequate for high-quality care. Only $33 \%$ felt that there were enough nurses to get the work done. ${ }^{10}$ Studies measuring nurse staffing have not supported these perceptions. All the studies find RN staffing stable or increasing. ${ }^{11-16}$

However, research examining the relationship between nurse staffing and the quality of care increasingly finds that better RN staffing correlates with higher quality. Initially, only three ${ }^{17-19}$ out of eight $^{17-24}$ studies found RN staffing to have a statistically significant negative relationship with patient mortality. However, when quality indicators more selective for nursing care are used, higher RN/patient or RN/nursing staff ratios have been associated with higher quality in all ${ }^{25-29}$ but one study. ${ }^{30}$ In four recent studies, RN staffing was significantly related to fewer nursing-sensitive adverse events. ${ }^{31-34}$

It is possible that a key reason for the discrepancy regarding $\mathrm{RN}$ staffing focuses on the status of licensed practical nurses (LPNs) in hospitals. To minimize costs and in response to $\mathrm{RN}$ supply constraints hospitals use a combination of RNs and LPNs for skilled patient care tasks. ${ }^{35-38}$ In a study assessing the roles of various nursing personnel, McGillis-Hall ${ }^{39}$ notes that recent nursing models substitute non-RN personnel for RNs through role delineation. LPNs carry out many of the skilled nursing tasks of RNs. On medicalsurgical wards RNs and LPNs may divide up the patient load, and carry out similar bedside tasks. ${ }^{40-42}$ LPNs are also increasingly used in critical care. ${ }^{43,44}$ However, RNs and LPNs differ in that RNs engage in more complex clinical judgments, ${ }^{45,46}$ and only RNs are capable of supervising nursing personnel, communicating with physicians, administering certain treatments and medications, and conducting overall patient care assessment and planning. ${ }^{41,47}$

Because RNs share much of their workload with LPNs, if LPN employment decreases, RN workload could be affected. Indeed, prior studies have demonstrated a decline in LPN staffing throughout the 1990s. ${ }^{14-16}$ Therefore, the actual patient load for RNs could have increased even though the documented patient load of RNs has not. This could be ascertained by looking at the patient load for licensed nurses (both RNs and LPNs).

Similarly, if adequate RN staffing is important for quality nursing care, as some studies suggest, and LPNs share patient care tasks with RNs, then we should find that adequate amounts of licensed nurses are important in providing quality patient care. As with RN staffing, insufficient licensed staff may affect the work process, resulting in hurried, delayed, omitted, fragmented, or erroneous care. This leaves patients prone to complications and hospital-acquired infections, slower recovery, or even death caused by complications or error. ${ }^{28,48-53}$ To assess these issues, this study examines the changes in licensed nurses, defined as RNs and LPNs, in Pennsylvania hospitals from 1991 to 1997, and the relationship of licensed nurse staffing with in-hospital patient adverse events.

\section{Materials and Methods}

\section{Research Design}

This study first examines the yearly percentage change in numbers of licensed nurses, their numbers in relation to patient load, and their skill mix. Patient load is assessed, first, through the actual numbers of patients cared for, and second, through the number of patients adjusted for hospital-level acuity. Acuity-adjusted patient load is important to examine given increases in patient severity over time. ${ }^{54-55}$

Second, this study examines whether lower levels and proportions of licensed nursing staff are associated with higher levels of in-hospital patient complications. The yearly incidence of six adverse events sensitive to nursing care are related to the hospitals' licensed nursing staff, the numbers of patients, hospital acuity, other hospital characteristics, and a trend variable. Adverse events are: atelectasis, decubitus ulcers, falls, pneumonia, postsurgical and treatment infections, and urinary tract infections. $31-34,56$

Counts of adverse events are used because this avoids spurious correlation between response and explanatory variables defined as rates with similar denominators (such as the number of patients), and because adverse events are not distributed normally given their low incidence, but more closely fit a Poisson distribution. To normalize the 
counts of adverse events to the patient population in the hospital, the number of patients for that year is included among the explanatory variables.

The explanatory variables are the numbers of licensed nurses and their proportion to the total nursing staff. These two variables are highly correlated, so as is common in nurse staffing studies, they are examined in separate regressions. ${ }^{31-34}$

Patient characteristics that may affect adverse events include their age, gender, race, ethnic status, and their level of severity upon admission. ${ }^{17,21-24,30}$ The MediQual severity measure described below includes these characteristics in one severity score.

The following hospital characteristics that typically are related to adverse events are also included: ownership status, hospital mergers, the number of board-certified physicians, and capacity utilization (occupancy rate/length of stay), a construct of two measures frequently used separately.17,20,22 The construction of capacity utilization significantly reduced bivariate correlation between the two separate measures, yet yielded a powerful indicator of efficiency: high values indicate the hospital had higher occupancy rates given length of stay, or low length of stay given occupancy rate, or high occupancy rate along with low length of stay. It was hypothesized that more efficient hospitals would have lower incidences of adverse events.

A final variable included in the analysis is a year marker that signifies the passage of time from 1991 to 1997. It is an unspecified trend variable that indicates the influence on adverse events of any changes in the hospital services market (eg, increases in managed care penetration) or in hospitals (eg, restructuring) that occurred over the time period.

\section{Measures}

Descriptive measures are the numbers of licensed nurses; the ratio of licensed nurses/patient load, with and without adjusting for patient acuity; and the proportion of licensed nurses/total nursing staff. These measures, and all measures below, are described in Table 1.

Patient load is measured through outpatientadjusted patient days of care, which equals the yearly number of patients in the hospital multiplied by their length of stay, plus estimated outpatient "days of care." The outpatient adjustment must be made because the staffing variables do not distinguish between in- and outpatient staff. With the outpatient adjustment, this measure is commonly referred to as "adjusted patient days of care" (APDC). APDC must be distinguished from measures that include further adjustment for hospital acuity.

For acuity adjustment, APDC are multiplied by hospital-level acuity score obtained by summing patient MediQual severity scores in each hospital, and dividing by the number of patients. Severity scores have 0 to 4 levels of risk, with 4 being the most severe. The scores are based on a regression model that includes patient characteristics and 23 key clinical findings abstracted from admission medical records, including vital signs, other physical findings, historical factors, and radiographic and laboratory findings. ${ }^{57-60}$ Some studies indicate that clinical-based severity measures, such as MediQual, are more consistent indicators of severity than diagnosis-based measures. ${ }^{61,62}$

For the analysis, the adverse events are yearly incidences of conditions that were either caused, or not prevented, by medical management ${ }^{28}$ that were extracted from the patient administrative records (ICD-9-CM codes). Both the medical and surgical patients in the hospital for the year constitute the patient cohort. This choice of cohort is consistent with a selection of adverse events that could arise from either medical or surgical conditions, and with prior studies. ${ }^{34}$ Adverse events are operationally defined using patient discharge records as described in Table 1. Explanatory measures are also defined in Table 1.

\section{Sample and Data Preparation}

National-level data sets that enable random sampling do not have data on LPNs or clinical patient severity for all the years in the study, whereas the following convenience-sample data contained the necessary measures for the analysis: The Pennsylvania Department of Health (PDH) and the American Hospital Association (AHA) furnished data on nursing personnel and hospital characteristics. The Pennsylvania Health Care Cost Containment Council (PHC4) provided patientlevel information.

Hard copy data from PDH was entered onto an Excel spread sheet and merged with AHA data. Patient records from PHC4 were coded for adverse events and patient-level measures were aggre- 
TABle 1. Operational Definition of Variables

\begin{tabular}{|c|c|c|}
\hline Variable & Operational Definition & Source \\
\hline \multicolumn{3}{|l|}{ Descriptive measures } \\
\hline Licensed nurses* & No. FTE† RNs + LPNs on hospital payroll as of June 30th yearly. & $\mathrm{PDH}$ \\
\hline Total nursing staff & No. FTE† RNs + LPNs + NA on hospital payroll as of June 30th yearly. & $\mathrm{PDH}$ \\
\hline Patient load & $\begin{array}{l}\text { Number of patient days per year in the hospital, including adjustment for } \\
\text { outpatients (adjusted patient days of care). }\end{array}$ & AHA \\
\hline $\begin{array}{l}\text { Licensed nurses/patient } \\
\text { load }\end{array}$ & (No. FTE† RNs + LPNs)/1,000 Adjusted Patient Days of Care. & $\begin{array}{l}\text { PDH, } \\
\text { AHA }\end{array}$ \\
\hline Hospital Acuity Score & $\begin{array}{l}\text { Patient's MediQual severity score (0-4), based on patient's admitting diagnosis, } \\
\text { comorbidties, age and other factors, summed to yearly hospital level and } \\
\text { divided by the No. patients. }\end{array}$ & PHC4 \\
\hline $\begin{array}{l}\text { Licensed nurses/ } \\
\text { acuity-adjusted patient } \\
\text { load }\end{array}$ & (No. FTE† RNs + LPNs)/1,000 APDC * Hospital Acuity Score. & $\begin{array}{l}\text { PDH, } \\
\text { AHA, } \\
\text { PHC4 }\end{array}$ \\
\hline $\begin{array}{l}\text { Licensed nurses/total } \\
\text { nursing staff* }\end{array}$ & No. FTE† Licensed nurses/No. FTE† total nursing staff. & $\mathrm{PDH}$ \\
\hline \multicolumn{3}{|l|}{$\begin{array}{l}\text { Analytical measures: } \\
\text { explanatory variables }\end{array}$} \\
\hline No. patients & Total number of patients in the hospital for that year. & PHC4 \\
\hline Aggregate hospital acuity & $\begin{array}{l}\text { MediQual severity score for each patient summed up for a yearly aggregate } \\
\text { hospital acuity level. }\end{array}$ & $\mathrm{AHA}$ \\
\hline Capacity utilization & Occupancy rate/ length of stay. & AHA \\
\hline Ownership status & For-profit or not-for-profit (government or private). & AHA \\
\hline Merger status & Whether hospital merged in last year. & $\mathrm{PDH}$ \\
\hline Board certified doctors & No. board certified physicians on hospital staff. & AHA \\
\hline Trend & Year marker. & \\
\hline \multicolumn{3}{|l|}{$\begin{array}{l}\text { Analytical measures: } \\
\text { response variables }\end{array}$} \\
\hline Incidence of: & $\begin{array}{l}\text { Yearly No. occurrences of adverse events per hospital extracted from patient } \\
\text { administrative records, defined as follows: }\end{array}$ & $\begin{array}{l}\text { All } \\
\text { PHC4 }\end{array}$ \\
\hline Atelectasis & $\begin{array}{l}\text { If major diagnostic category is not diseases and disorders of the respiratory } \\
\text { system, and if secondary diagnosis is atelectasis. }\end{array}$ & \\
\hline Decubitus ulcers & $\begin{array}{l}\text { If admission or primary diagnoses are not decubitus ulcer, and if patient did not } \\
\text { come from another health care facility, and secondary diagnosis code is } \\
\text { decubitus ulcer. }\end{array}$ & \\
\hline Falls & $\begin{array}{l}\text { If admission diagnosis or primary diagnosis are not fracture or injury, and if } \\
\text { ecode is fall from commode, toilet, wheelchair, from other furniture, from } \\
\text { bumping against another object, from the same level by slipping, tripping or } \\
\text { stumbling, or as an accidental fall from bed, chair, etc. }\end{array}$ & \\
\hline Pneumonia & $\begin{array}{l}\text { If major diagnostic category is not diseases and disorders of the respiratory } \\
\text { system, and if secondary diagnosis is pneumonia. }\end{array}$ & \\
\hline $\begin{array}{l}\text { Postsurgical or } \\
\text { posttreatment infection }\end{array}$ & $\begin{array}{l}\text { If admission diagnosis or primary diagnosis are not postoperative infection, infected } \\
\text { postoperative seroma, infection due to indwelling urinary catheter, post-op } \\
\text { abscess, post-op septicemia, infection or sepsis or septicemia following infusion, } \\
\text { injection, transfusion, or vaccination, and complications of obstetrical surgical } \\
\text { wounds; and if secondary diagnosis is any of the above. }\end{array}$ & \\
\hline Urinary tract infection & $\begin{array}{l}\text { If major diagnostic category is not diseases and disorders of the kidney and } \\
\text { urinary tract, male reproductive system, or female reproductive system, and } \\
\text { if secondary diagnosis is urinary tract infection. }\end{array}$ & \\
\hline
\end{tabular}

\footnotetext{
*Also analytical explanatory variable.

${ }^{\dagger}$ FTEs are defined as one full-time position (30 hours per week or more) or two part-time positions (up to 30 hours per week).
} 
gated to yearly hospital counts in SAS. Finally, this was merged with the PDH/AHA data into a SAS data set. In this process, five hospitals in the PDH/AHA data were dropped because they were not in the PHC4 data set. Including missing data caused by hospital openings, mergers and closings, the combined data set contained 211 hospitals yearly, for a total of 1477 during 7 years.

\section{Data Analysis}

The yearly percentage change in licensed nursing staff categories was calculated in SAS as follows: [(mean value for nursing staff in year $\mathrm{t}_{\mathrm{t}+1^{-}}$ mean value in year $\left.{ }_{t}\right) /$ mean value in year ${ }_{t}{ }^{*} 100$, where $t=1991$ to 1996 . Total percentage change was evaluated using [(mean value for nursing staff in 1997-mean value in 1991)/mean value in 1991]*100.

To estimate the relationship between licensed nurse staffing and adverse events, the following Poisson regression model was utilized:

$\mu(\mathbf{x})=\{\mathrm{N}(\mathbf{x})\}\{g(\beta \mid \mathbf{x})\}$

where $\mu(\mathbf{x})=$ the number of adverse events,

$\mathrm{N}(\mathbf{x})=$ the number of patients,

$\{g(\beta \mid \mathbf{x})\}=$ the exponential function of explanatory

variables.

A random effects component $u_{\mathrm{i}}$ was added to this model to control for the individual effects of the repeated measures (seven measures from each hospital). $U_{i}$ is the random disturbance characterizing the $i$ th observation, is normally distributed, and is constant over time.

The full equation can be rewritten as:

$\# \mathrm{AE}=(\# \text { patients })^{*} \exp \left\{\beta 1+\beta 2^{*}(\#\right.$ licensed nurses or licensed nurses/total nursing staff)

$+\beta 3^{*}$ (severity) $+\beta 4^{*}$ (ownership status)

$+\beta 5^{*}$ (merger status) $+\beta 6^{*}$ (capacity utilization)

$+\beta 7^{*}$ (\# certified doctors) $+\beta 8^{*}$ (trend) $\left.+\mu+\epsilon\right\}$.

The regression was analyzed as a log-linear function of this Poisson random effects model:

$$
\log \left\{n_{i}\right\}=\log \left\{N_{i}\right\}+x^{\prime} \beta+u+\varepsilon .
$$

Each of the six adverse events categories was regressed separately on two sets of equations: one with the numbers of licensed nurses, the other with licensed nurses/total nursing staff. The NLMixed procedure in SAS was used. The procedure fits nonlinear models through a maximum likelihood function.

\section{Results}

Table 2 shows that the Pennsylvania hospital employment of licensed nurses rose from 1991 to 1993 and from 1996 to 1997, and fell 1993 to 1996, resulting in no change overall. APDC shows a similar pattern, except that it declined even more from 1994 to 1997, and ended with an overall 4.3\% decrease. The result is that licensed nurse/1000 APDC increased for most of the time period, decreased from 1992 to 1993 and from 1996 to 1997 , and on the whole, increased $4 \%$. Because the patient load per licensed nurse is the inverse of this measure, it is apparent that patient load increased for only 2 years. When APDC is additionally adjusted for hospital acuity, the picture changes significantly. Because hospital acuity increased 21\% from 1991 to 1997, licensed nursing staff/1000 acuity-adjusted APDC fell nearly every year, for a total of $14.2 \%$. This indicates that the acuity-adjusted patient load, or the intensity of nursing care, increased.

Finally, total nursing staff declined less than licensed nurses from 1994 to 1996 and increased more from 1996 to 1997. Therefore, licensed nurses/total nursing staff fell from 1994 to 1997, resulting in a $2 \%$ decrease overall.

Regression results were significant for most explanatory variables with most adverse events. As expected, hospitals with more patients were associated with a greater number of adverse events in all categories $(P<0.0001)$. Similarly, hospitals with higher acuity related to significantly more of all types of adverse events $(P<0.0001)$. Hospitals having better capacity utilization had fewer adverse events of all types $(P<0.0001)$. More cases of atelectasis occurred in for-profit hospitals $P=0.0378$ ), otherwise forprofit status was not statistically related to the remaining adverse events. Hospital mergers were related to an increase in the number of falls and urinary tract infections $(P<0.0001$ for both), but conversely to a decrease in pneumonia $(P<0.0001)$. The number of board certified physicians was related to fewer falls $(P<0.0001)$, pneumonia $(P<0.0001)$, and urinary tract infections $(P=0.0178)$, was not related to atelectasis and decubiti, and was positively 
Table 2. Mean Values and Percentage Change in Licensed Nursing Staff Categories, Adjusted Patient Days of Care, and Hospital Acuity in Pennsylvania Hospitals, 1991-1997

\begin{tabular}{|c|c|c|c|c|c|c|c|c|c|}
\hline & 1991 & 1992 & 1993 & 1994 & 1995 & 1996 & 1997 & $\begin{array}{l}\text { Overall } \\
\text { Mean }\end{array}$ & $\begin{array}{c}\% \Delta \\
1991-7\end{array}$ \\
\hline Licensed Nurses & 281 & 292 & 298 & 286 & 280 & 276 & 281 & 284 & - \\
\hline$\% \Delta$ from prior year & - & 4.3 & 1.7 & -4.0 & -1.7 & -1.4 & 1.8 & - & 0.0 \\
\hline Total Nursing Staff & 332 & 345 & 352 & 336 & 331 & 329 & 340 & 337 & - \\
\hline$\% \Delta$ from prior year & - & 3.9 & 2.0 & -4.5 & -1.8 & -0.6 & 3.3 & - & 2.1 \\
\hline $\begin{array}{l}\text { Adjusted Patient } \\
\text { Days of Care } \\
\text { (APDC) }\end{array}$ & 83,766 & 86,610 & 90,025 & 84,284 & 82,353 & 80,373 & 80,953 & 83,924 & - \\
\hline$\% \Delta$ from prior year & - & 2.4 & 3.5 & -6.4 & -2.3 & -2.4 & 1.1 & - & -4.3 \\
\hline $\begin{array}{l}\text { License Nurse/1,000 } \\
\text { APDC }\end{array}$ & 3.28 & 3.37 & 3.32 & 3.38 & 3.39 & 3.43 & 3.41 & 3.3 & - \\
\hline$\% \Delta$ from prior year & - & 2.7 & -1.5 & 1.8 & 0.4 & 1.3 & -0.7 & - & 3.9 \\
\hline $\begin{array}{l}\text { Hospital acuity } \\
\text { Score }\end{array}$ & 0.967 & 1.076 & 1.066 & 1.117 & 1.158 & 1.113 & 1.173 & 1.105 & - \\
\hline$\% \Delta$ from prior year & - & 11.3 & -0.9 & 4.8 & 3.7 & -3.8 & 5.4 & - & 21.3 \\
\hline $\begin{array}{c}\text { Licensed Nurse/ } \\
\text { 1,000 Acuity- } \\
\text { Adjusted } \\
\text { APDC }\end{array}$ & 3.6 & 3.3 & 3.25 & 3.19 & 3.11 & 3.25 & 3.09 & 3.25 & - \\
\hline$\% \Delta$ from prior year & - & -8.4 & -1.3 & -1.8 & -2.6 & 4.4 & -5.0 & - & -14.2 \\
\hline $\begin{array}{l}\text { Licensed Nurse/ } \\
\text { Total Nursing } \\
\text { Staff }\end{array}$ & 0.845 & 0.847 & 0.85 & 0.852 & 0.851 & 0.848 & 0.826 & .847 & - \\
\hline$\% \Delta$ from prior year & - & 0.2 & 0.3 & 0.2 & -0.1 & -0.3 & -2.6 & - & -2.2 \\
\hline
\end{tabular}

related to more postsurgical infections $(P=0.0003)$. Finally, the results for the trend variable indicate that market and hospital processes that increased over time were associated with an increase in all adverse events $(P<0.0001)$.

Table 3 presents the estimates and significance for licensed nurse staffing variables. It also shows the mean values for each adverse event and estimates the percentage change in each of the adverse events given a $10 \%$ change in the licensed nursing staff category. Hospitals with more licensed nurses (keeping the number of patients constant) had significantly lower incidences of atelectasis, decubiti, falls, and urinary tract infections. However, they had significantly higher rates of pneumonia. Hospitals with a greater proportion of licensed nurses/total nursing staff had significantly lower rates of decubiti and pneumonia. Licensed nurse/total nursing staff had no significant association with the other adverse events with the exception of a positive relationship to falls.

\section{Discussion}

The descriptive results indicate that while licensed nurses' actual patient load increased for only two short periods, the intensity of patient care increased for nearly the entire period. At the same time, the fall in skill mix, caused by both a decline in licensed nurses and to an increase in unlicensed nurses, along with the increase in hospital acuity, indicates that the proportion of skilled nurses available to deal with increasingly sicker patients declined, and that RNs had more supervisory responsibilities at a time in which their bedside nursing care was becoming more intense and demanding.

The results of the regression analysis reveal several important points. The significant negative relationship of capacity utilization with all adverse events, may indicate that efficient hospitals have higher quality patient care, but also begs the question of how this interacts with nurse staffing. Because high capacity utilization implies rapid 


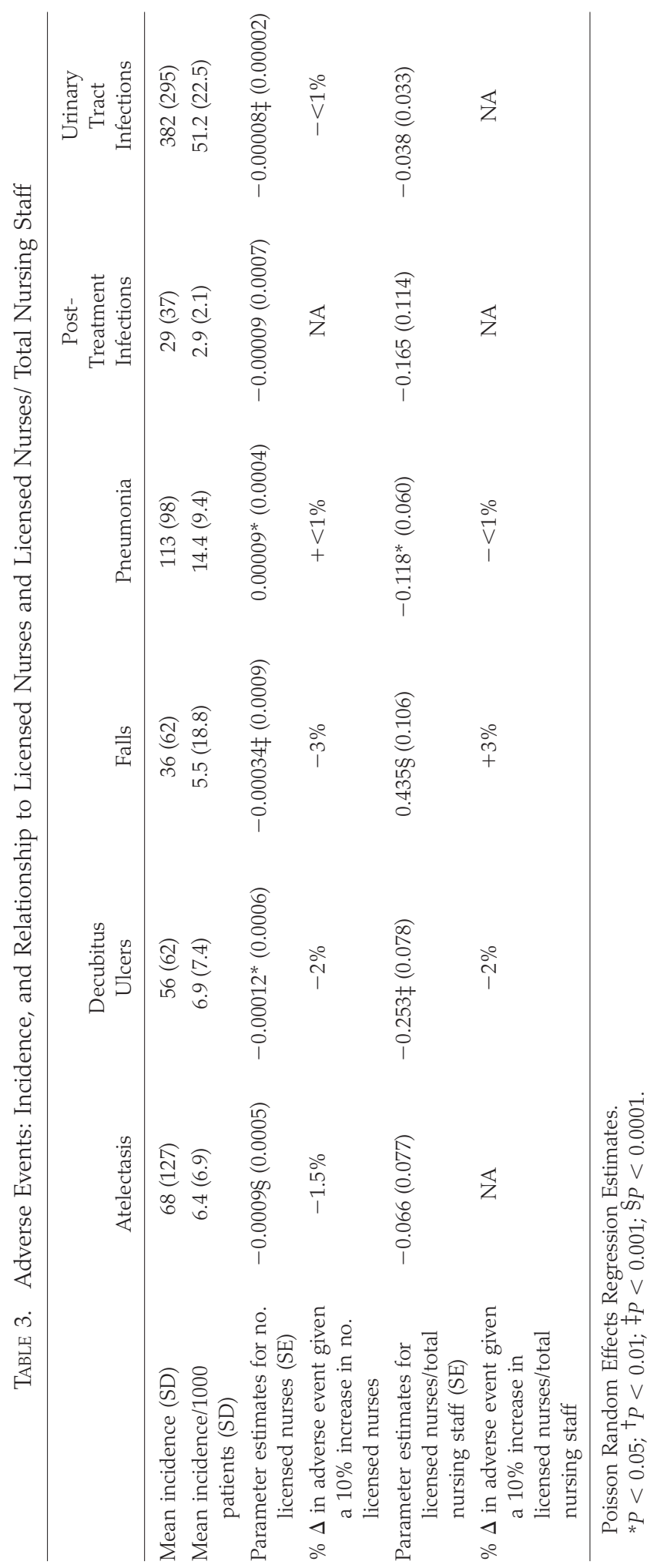

Copyright ( ) Lippincott Williams \& Wilkins. Unauthorized reproduction of this article is prohibited. 
patient turnover, fully occupied beds, or both, under conditions of low licensed nurse staffing it may augment the negative patient outcomes caused by the low staffing ratios. Therefore, capacity utilization may play a positive role only when it is accompanied by adequate staffing.

The strong positive association between the trend variable and adverse events raises the following question: What events occurred over this time period that contributed to an increase in adverse events? Some factors under hospital control that could have contributed to this result are nursing model, financial, managerial, and physical hospital changes. Buerhaus and Needleman ${ }^{56}$ report that several of these questions are being explored in studies currently underway.

Concerning the licensed nursing staff variables, results indicate that there is a statistically strong relationship between higher numbers and proportion of licensed nurses and the lower incidence of several adverse events. To speculate on the clinical effect, the amount of increase or decrease in the adverse event given a change in staffing was estimated by multiplying the parameter estimate times a change in the staff and taking the exponential of that product (because of the log-linear regression) (Table 3). Given a 10\% increase in the mean value of licensed nurses (an increase of 28), atelectasis is estimated to decrease by $1.5 \%$, decubitus ulcers by $2 \%$, falls by $3 \%$, and urinary tract infections by less than 1\%. A $10 \%$ increase in licensed nurse/total nursing staff (an increase of 0.083 ) is calculated to decrease decubitus ulcers by $2 \%$ and pneumonia by less than $1 \%$. A $10 \%$ increase in licensed nurses, however, is estimated to increase pneumonia by less than $1 \%$, whereas the same increase in licensed nurse/total nursing staff is calculated to increase falls by $3 \%$.

The reduction of adverse events through increased licensed staffing may currently seem to be unattainable because of the higher costs associated with hiring and training more licensed nurses, especially given hospitals' financial constraints. However, adverse events themselves are costly. Pressure ulcers, for example, result in up to five times the average length of stay. ${ }^{56}$ The cost savings from the decrease in adverse events may offset the added costs in staffing.

In this study the number of licensed nurses is a stronger predictor of adverse events than the proportion of licensed nurses to total nursing staff. This would suggest that if the level of licensed nurses is sufficient for high quality patient care, a high skill mix is not crucial. In fact, if the level of licensed nursing staff is adequate, lower skill mix could indicate the higher use of nursing assistants as complementary personnel, which could contribute positively to patient care. A high skill mix in the presence of adequate numbers of licensed nurses likely indicates a primary nursing model, which utilizes a high proportion of RNs and is expensive to maintain. Results here, instead, tend to support the use of team nursing as long as the numbers of licensed nurses are adequate.

We speculate that the relationships between licensed nursing staff and falls and pneumonia can be explained as follows: Because the prevention of falls involves keeping a close watch on patients and providing basic nursing care, such as ambulation and toileting, nursing assistants, who are typically employed for these tasks, may play a role. This means that a higher proportion of unlicensed nurses, and therefore lower skill mix, contributes to preventing falls. For pneumonia, many of the patients exposed to iatrogenic pneumonia will have undergone surgery, or had trauma or a major medical episode that places them in intensive care. Therefore, a higher proportion of licensed nurses is significant in preventing pneumonia.

The limitations of the analysis portion of the study focus primarily on the reliability and validity of the measures. The utilization of administrative data to ascertain complications during hospitalization has been controversial. ${ }^{63,64}$ Validity concerns are whether the conditions represented by ICD9-CM codes were present, ${ }^{65,66}$ or whether the algorithms for ascertaining complications can distinguish between conditions present upon admission, versus those occurring in the hospital. ${ }^{66}$ Reliability of data gathered from multiple sources is also an issue. ${ }^{64}$ However, it believed that the data can be useful for identifying quality problems. ${ }^{67-69}$ In addition, the Pennsylvania records used in this study have been identified as "intermediate steps in converting clinical observations to an electronic format," 59 and are cleaned up in an effort to produce as reliable data as possible. ${ }^{70}$

Poor reporting compliance of hospitals in the early years of the data collection ${ }^{70}$ may have reduced the calculated rates of adverse events. Reporting inconsistencies, such as the initial use of only five fields for secondary diagnosis, which increased to eight fields in 1994, may have led to the omission of some adverse events in the early years of the study. Finally, although Iezzoni et al ${ }^{63,69-71}$ have assessed the general validity of 
measures of this type, outside of the developing Complications Screening Program, ${ }^{66,69}$ there is no standardization of coding procedures among researchers. For this study, although internal validity was not assessed, the measures were coded in a manner consistent with prior research.

Some solutions to the data and measurement problems discussed here have been addressed in articles by Iezzoni et al.59,63-69 One significant suggestion has been to improve ICD-9-CM coding by the requirement of date markers for all secondary diagnoses so that patient comorbidities can be better distinguished from complications arising from the patient's stay. ${ }^{64}$

\section{Policy Implications}

Results underscore the importance of adequate licensed nurse staffing in US hospitals. Specific considerations are as follows: First, given the increases in patient acuity and patient care intensity, when considering licensed staffing targets, a flat licensed nurse/patient ratio, without consideration of patient acuity, may over or underestimate staffing needs in a particular unit or institution at a given point in time. Therefore, the need to develop or reintroduce flexible staffing systems that take into account daily patient severity are essential to both adequate and cost-efficient staffing. Second, steps must be taken by hospitals and policy makers to increase the supply of nurses, including drawing nurses back and attracting more people into nursing. This can be accomplished by making employment in nursing more attractive and providing assistance in nursing education. In making employment more attractive, most nurses say that working conditions are the biggest issue pushing them away from nursing. ${ }^{72}$ Because understaffing is part of the poor working conditions, a vicious cycle may exist of hospitals not having enough nurses because they do not have enough nurses. Finally, as this study indicates, it will be important to attempt to bring back both RNs and LPNs in some, as yet undetermined, mix, and to attract new young people to both occupations.

\section{References}

1. Buerhaus PI. Economics of managed competition and consequences to nurses: Part I. Nursing Economics 1994;12:10-17.
2. Buerhaus PI. Economics and reform: forces affecting nurse staffing. Nursing Policy Forum 1995;1:9-14.

3. Reardon J, Reardon L. The restructuring of the hospital services industry. J Econ Issues 1995;29:10631081.

4. Buerhaus PI. Economics of managed competition and consequences to nurses: Part II. Nursing Econ 1994;12:75-80, 106.

5. Spetz J. The effects of managed care and prospective payment on the demand for hospital nurses: evidence from California. Health Serv Res 1999;34:9931010.

6. Federation of Nurses and Health Professionals. Nurse staffing: the content of care. Testimony prepared by the FNHP, AFT, AFL-CIO, for the Institute of Medicine, National Academy of Sciences; 1994.

7. Gordon S. Is there a nurse in the house? The Nation 1995;2:199-202.

8. Shindul-Rothschild J, Berry D, LongMiddleton E. Where have all the nurses gone? Final results of our patient care survey Am J Nurs 1996;96:2539.

9. Service Employees International Union. The National Nurse Survey. Washington, DC: Public Department of Service Employees International Union; 1993.

10. Aiken L, Clarke S, Sloane D, et al. Nurses' report on hospital care in five countries. Health Aff 2001;20:43-53.

11. Aiken LH, Sochalski J, Anderson GF. Downsizing the hospital nursing workforce. Health Aff 1996;15:88-92.

12. Anderson GF, Kohn LT. Hospital employment trends in California, 1982-1994. Health Aff 1996:15: 152-158.

13. Bond CA, Raehl CL. Changes in pharmacy, nursing, and total personnel staffing in U.S. hospitals, 1989-1998;Am J Health Syst Pharm 2000;57:970-974.

14. Spetz J. Hospital employment of nursing personnel. J Nurs Adm 1998;28:20-27.

15. Buerhaus PI, Staiger DO. Trouble in the nurse labor market? Recent trends and future outlook Health Aff 1999;18(1):214-222.

16. Kovner CT, Jones CB, Gergen PJ. Nurse staffing in acute care hospitals, 1990-1996. Policy: Politics and Nursing Practice 2000;1:194-204.

17. Hartz AJ, Krakauer H, Kuhn EM, et al. Hospital characteristics and mortality rates. N Engl J Med 1989;321:1720-1725.

18. Krakauer H, Bailey RC, Skellan KJ. Evaluation of the HCFA model for the analysis of mortality following hospitalization. Health Serv Res 1992;27:317335. 
19. Manheim LM, Feinglass J, Shortell SM, et al. Regional variation in medicare hospital mortality. Inquiry 1992;29:55-66.

20. Scott RW, Forrest WH Jr., Brown, B. W. Jr. Hospital structure and postoperative mortality and morbidity. In: Organizational Research in Hospitals. Chicago, IL: Blue Cross Association; 1976:72-89.

21. Shortell SM, Hughes EFX. The effects of regulation, competition, and ownership on mortality rates among hospital inpatients. N Engl J Med 1988;318:11001107.

22. Al-Haider AS, Wan TH. Modeling organizational determinants of hospital mortality. Health Serv Res 1991;26:303-323.

23. Silber JH, Williams SV, Krakauer $\mathbf{H}$, et al. Hospital and patient characteristics associated with death after surgery. Med Care 1992;30:615-627.

24. Knaus WA, Draper EA, Wagner DP, et al. An evaluation of outcomes from intensive care in major medical centres. Ann Intern Med 1986;104:410-418.

25. Aiken LH, Smith HL, Lake ET. Lower medicare mortality among a set of hospitals known for good nursing care. Med Care 1994;32:771-787.

26. Shindul-Rothschild J, Long-Middleton EL, Berry D. 10 keys to quality care. Am J Nurs 1997;97:3543.

27. Flood SD, Diers D. Nurse staffing, patient outcome and cost. Nursing Management 1988;19:34-41.

28. Brennan TA, Leape LL, Laird NM, et al. Incidence of adverse events and negligence in hospitalized patients: Results of the Harvard Medical Practice Study I. N Engl J Med 1991;324:370-376.

29. Kramer M, Schmalenberg C. Magnet hospitals: Institutions of excellence, Part I and II. J Nurs Adm 1988;18:11-24.

30. Wan TTH, Shukla R. Contextual and organizational correlates of the quality of hospital nursing care. Q Rev Bull 1987;13:61-65.

31. American Nurses Association. Implementing Nursing's Report Card: A Study of RN Staffing, Length of Stay and Patient Outcomes. Washington, DC: ANA; 1997.

32. Blegen MA, Goode CJ, Reed L. Nurse staffing and patient outcomes. Nurs Res 1998;47:43-50.

33. Kovner C, Gergen PJ. Nurse staffing levels and adverse events following surgery in US hospitals. Image: J Nurs Scholarsh 1998;30:315-321.

34. Needleman J, Buerhaus $\mathbf{P}$, Mattke S, et al. Nurse-staffing levels and the quality of care in hospitals. N Engl J Med 2002;346:1715-1721.

35. Kenney P. Maintaining quality care during a nursing shortage using licensed practical nurses in acute care. J Nurs Care Qual 2001;15:60-68.
36. Mullinix C. ... And what about the LPN? J Prof Nurs 1991;7:6

37. Staiger D, Spetz J, Phibbs C. Is there monopsony in the labor market? Evidence from a natural experiment National Bureau of Economic Research 1999; Working Paper 7258. Available at: URL http://www.nber.org/papers/w7258.

38. Reeves D. A Licensed Practical Nurse/Licensed Vocational Nurse's guide to the changing healthcare system. Gastroenterol Nurs 1997;20:54-56.

39. McGillis-Hall L. Staff mix models: complementary or substitution roles for nurses. Nursing Admin Q 1997;21:31-39.

40. Freeman BA, Coronado JR. The nursing shortage: Dynamics and solutions. A supportive clinical practice model. Nurs Clin North Am 1990;25:551-560.

41. US Department of Labor, Bureau of Labor Statistics. Occupational Outlook Handbook; 2000-2001.

42. Clark T, Thurston N. The RN and LPN skill mix. Can Nurse 1994;90:19-22.

43. Ingersoll GL. Licernsed practical nurses in critical care areas: Intensive care unit nurses' perceptions about their role. Heart Lung 1995;24:83-88.

44. Erikson LR, Quandt B, Teinert D, et al. A registered nurse-licensed vocational nurse partnership model for critical care nursing. J Nurs Adm 1992;22:2838 .

45. Manthey M. The role of the LPN or...the problem of two levels. Nursing Management 1989;20:26, 28.

46. Adams DA, Largen CW. Is There a Difference Between an RN and an LPN? J Nurs Adm 1993;23:5, 28.

47. Davis K. Non-nursing functions: Our readers respond. Am J Nurs 1982;82:1857-1860.

48. Servellen GV, Schultz MA. Demystifying the influence of hospital characteristics on inpatient morality rates. J Nurs Adm 1999;29:39-47.

49. Robertson RH, Dowd SB, Hassan M. Skillspecific staffing intensity and the cost of hospital care. Health Care Manage Rev 1997;22:61-71.

50. Ahmed DS, Fecik S. Med errors: The fatigue factor. Am J Nurs 1999;99:12.

51. Dugan J, Lauer E, Bouqout Z, et al. Stressful nurses: The effect on patient outcomes. J Nurs Care Qual 1996;10:46-58.

52. Motowidlo SJ, Manning MR, Packard JS. Occupational stress: Its causes and consequences for job performance. J Appl Psychol 1986;71:618-629.

53. Hendrickson G, Doddato TM, Kovner CT. How do nurses use their time? J Nurs Adm 1990;20:3137. 
54. Buerhaus P. Lucian Leape on the cause and prevention of errors and adverse events in health care. Image: J Nurs Scholarsh 1999;31:281-286.

55. Rosen A, Ash A, McNiff K, et al. The importance of severity of illness adjustment in predicting adverse outcomes in the Medicare population. J Clin Epidemiol 1995;48:631-643.

56. Buerhaus $\mathbf{P}$, Needleman J. Policy implications of research on nurse staffing and quality of patient care. Policy, Politics Nursing Practice 2000;1:5-15.

57. Iezzoni LI, Moskowitz MA. A clinical assessment of MedisGroups. JAMA 1988;260:3159-3163.

58. Thomas JW, Ashcraft MLF. Measuring severity of illness: Six severity systems and their ability to explain cost variations. Inquiry 1991;28:39-55.

59. Jollis JG, Romano PS. Pennsylvania's focus on heart attach-Grading the scorecard. N Engl J Med 1998;338:983-987.

60. Iezzoni LI, Ash AS, Shwartz M, et al. Judging hospitals by severity-adjusted mortality rates: The influence of the severity-adjustment method. Am J Public Health 1996;86:1379-1387.

61. Iezzoni LI, Ash AS, Shwartz M, et al. Predicting who dies depends on how severity is measured: Implications for evaluating patient outcomes Ann Intern Med 1995;123:763-770.

62. Hughes JS, Iezzoni LI, Daley J, et al. How severity measures rate hospitalized patients. J Gen Intern Med 1996;11:303-311.
63. Iezzoni LI, Daley J, Heeren T, et al. Using administrative data to screen hospitals for high complication rates. Inquiry 1994;31:40-55.

64. Romano PS, Mark DH. Bias in the coding of hospital discharge data and its implications for quality assessment. Med Care 1994;32:81-90.

65. McCarthy EP, Iezzoni LI, Lawthers AG, et al. Does clinical evidence support ICD-9-CM diagnosis coding of complications? Med Care 2000;38:868-876.

66. Lawthers AG, McCarthy EP, Davis RB, et al. Identification of in-hospital complications from claims data: Is it valid? Med Care 2000;38:785-795.

67. Geraci JM. In-hospital complication occurrence as a screen for quality-of-care problems: What's next? Med Care 2000;38:777-780.

68. Iezzoni LI. Assessing quality using administrative data. Ann Intern Med, Part 2, 1997;127:666-674.

69. Weingardt S, Iezzoni L, Davis $\mathbf{R}$, et al. Use of administrative data to find substandard care: validation of the complications screening program. Med Care 2000;38:796-806.

70. PHC4. Field Descriptions, 1999.

71. Elixhauser A, Steiner C, Harris DR, et al. Comorbidity measures for use with administrative data. Med Care 1998;36:8-27.

72. US GAO. Nursing workforce: Emerging nurse shortages due to multiple factors. Report to the Chairman, Subcommittee on Health, Committee on Ways and Means, House of Representatives July 2001; GAO-01944. 